\title{
Preface to the English- Language Edition
}

Drawing: this word in English suggests drawing out, stretching, and extracting. One can draw a line and draw a lesson. In French, one can draw out [tirer] a line or a lesson, but it is impossible to draw [dessiner] a lesson. Or rather, dessiner a lesson in French means something entirely different from "drawing" it. It would be to give an illustration, a visual representation of its contents, as when Plato asks his reader to draw a line in the mind that he will then divide into proportional segments in order to better understand the relation between the sensible and intelligible.

In French, dessiner a lesson is to make it be seen, to show and present it to an intuitive grasp. Tirer a lesson is to gather the lessons learned from a specific event that itself is not a lesson: for example-and again from Plato-to conclude from Socrates' moral qualities that physical ugliness can harbor a wealth of ideas. 
To show, to conclude, ostension, inference: gestures that, indeed, come together by way of one or another fine point, whether it is the point of a stylus, a finger, or a mind. However, that does not mean that these terms and their translation into different languages end up by overlapping one another. On the contrary-it is well known that there is never any homothety between languages, and precisely this lack gives to the task of translation its pleasurable and disturbing character. When I read drawing in English, knowing that I ought to be thinking of dessin, I feel myself carried far away on a sea of complexity, all the while knowing that there will be something to discover, an island of sense, or even just a current or turbulent zone.

This is also why one experiences so much gratitude to whoever holds the rudder of this perilous navigation-in this case, the sturdy hands of Philip Armstrong. (At the edge of the ocean, Helen Tartar sets out beacons and markers for landing.)

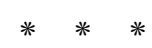

Between drawing out and showing-an asymptotic contact - there is something to discover. To show, to make something seen, to designate-designare - is also what accompanies the de-monstration through which a conclusion or lesson is drawn. One draws-one traces or extracts-in order to show. One shows by extending or spreading out in front of oneself. Better, in order to show something well, in order to render it fully manifest, one must not cease drawing (if only to draw attention), and in order to draw out (trace or pull), one must not lose sight of the invisible 
extremity of the mark [trait], the point by which the line advances and loses itself beyond itself in its own desire.

The gesture of showing by extending-extending in order to show or bring to light, extracting the lineament and incision of a form, contour, sense, or idea from the shadow or a compact mass-such is the gesture of existing. A sketch (Entwurf), Heidegger says, a term for which one retains above all the meaning of jet (werfen - "throwing, casting"), of projection toward what continues to come [le non-advenu], leaving in shadow the value of the mark, the tracing out, the form in the process of forming itself.

To exist is to sketch oneself [s'esquisser]. One would like to write s'exquisser - to open oneself to a form which shows itself in the movement of its uprising [surgissement]. No one would consent to live if they did not experience this desire-to open oneself to the desire of (letting oneself) being drawn to the outside.

\section{J-L.N.}

August 2012 
This page intentionally left blank 
The Pleasure in Drawing 
This page intentionally left blank 